\title{
Experimental Investigation of Oblique Laser Shock Processing on Aero-engine Fan Shaft
}

\author{
Zhang Pei $\mathrm{Yu}^{1}{ }^{1} \mathrm{a}^{*}$, Wang Cheng ${ }^{1}$, Chai Yan ${ }^{1}$ \\ ${ }^{1}$ Science and Technology on Plasma Dynamics Laboratory, Air Force Engineering University, \\ Xi'an, Shaanxi 710038, China \\ azpy7716061@163.com
}

\begin{abstract}
Keywords: Fan shaft, Circular bead, Oblique laser shock, Residual stress, Nanocrystallines, Rotary bending fatigue test
\end{abstract}

\begin{abstract}
The circular bead of aero-engine fan shaft was obliquely shocked by laser shock processing (LSP). After oblique laser shocked, the residual stress and microstructure characteristic of fan shaft were investigated and analyzed. The rotary bending fatigue tests and fracture analysis were also conducted. With oblique laser shocking, refinement of the martensite lamellar structure with a depth of $100 \mu \mathrm{m}$ was observed and the structure in the outermost layer of $15 \mu \mathrm{m}$ depth refined to $5 \sim 30$ $\mathrm{nm}$. Beside, a preferable residual stress distribution which can release the stress concentration of circular bead was acquired after LSP.In addition, the rotary bending fatigue life of fan shaft increased by $150 \%$ after LSP. Fracture analysis showed that the fatigue initiation migrated to inner materials and the crack growth speed of fan shaft reduced by LSP. It can come to a conclusion that LSP is a high-efficient surface treatment method to treat the stress concentration area of components.
\end{abstract}

\section{Introduction}

The aero-engine worked chronically in high-temperature, high-pressure, high-speed rotation harsh environment,and its fan shaft not only endured the centrifugal loads, bending loads and high-temperature loads, but also viberation, fatigue, exposure extrusion ,fretting wear and other aspects of effect. The surface proned to micro-cracks and triggered the fatigue damage, seriously affecting flight safety [1]. A certain type of engine's fan shaft adapter fillet was a axial-shaft of trasition angle and its wall thickness was thin, proning to stress concentration and caused security risks. During the service of engines, there existed fatigue fracture failure, severely reducing the engine's reliability.

It was important to harden the stress concentration surface, which was prone to crack initiation, improving the fatigue resistance, the reliability and life extension of the engine components. Currently, for the rounded, curved and other complex part, engineer strengthening mainly methods were quenched, nitrification, USP and LSP [2-4], forming sclerotic layer and residual compressive stress layer, improving the fatigue resistance of the parts.

Yinghong Li, Qipeng, Li el at [5, 6]. dealt with active link adapter $\mathrm{R}$ and turbine blades simulation $\mathrm{R}$ specimen in LSP, respectively improving the fatigue life 4. 25 -fold and 0. 67-fold. In order to extend the life of fan shaft, reducing the failure rate, the paper dealt with the fan shaft adapter rounded in oblique laser shock processing, improving the fatigue performance of the fan shaft, solving the problem induced by rounded stress concentration. The paper analyzed the residual stress distribution, microstructure, rotating bending fatigue properties and fracture characteristics, and discussed the stress of shaft parts and the lamellar structure mechanism of martensitic layer.

\section{Testing Material and Method}

The fan shaft material was $1 \mathrm{Cr} 11 \mathrm{Ni} 2 \mathrm{~W} 2 \mathrm{MoV}$ martensitic stainless steel by forging, heat treatment, stabilizing tempering, grinding, polishing and other processes processing. The transfer fillets was transition fillet from big shaft to middle shaft, the big shaft diameter was $72 \mathrm{~mm}$, the small shaft 
diameter is $52 \mathrm{~mm}$, the transition fillet radius was $3 \mathrm{~mm}$ and the thickness was $6 \mathrm{~mm}$. According the working conditions of the characteristics of the fan shaft, the researcher simulate the force condition when it highly speed rotated, by fixing the small shaft, loading torsional load to the big shaft, and the load torque is $2256.3 \mathrm{~N} \cdot \mathrm{m}$. The fan shaft static analysis results were shown in Fig. 1(a). Dynamic analysis on the fan shaft, a first-order vibration modes under stress distution was shown in Fig. 1(b). From the results, either the static analysis or the dynamic analysis, the fan shaft adapter rounded corner was stress concentration area, and the stress concentration was shown in arc central location, decreasing along the axis and the yearning.

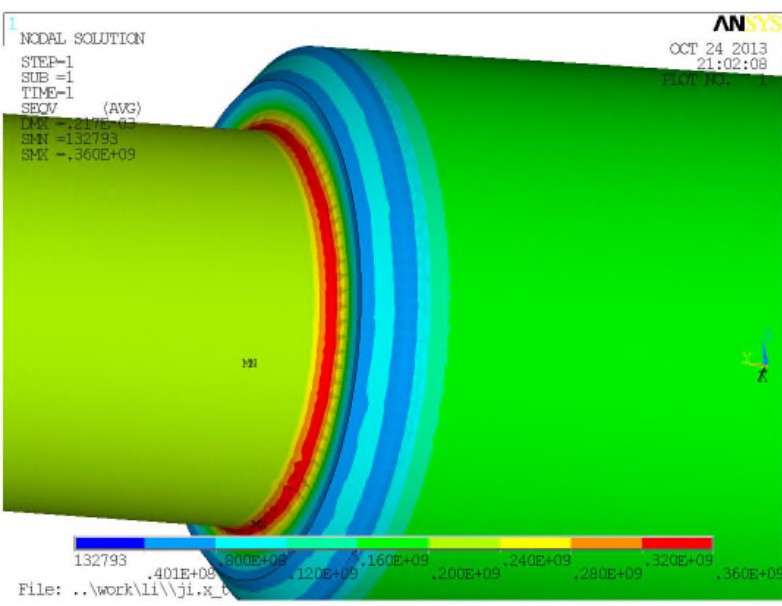

(a) Static stress distribution

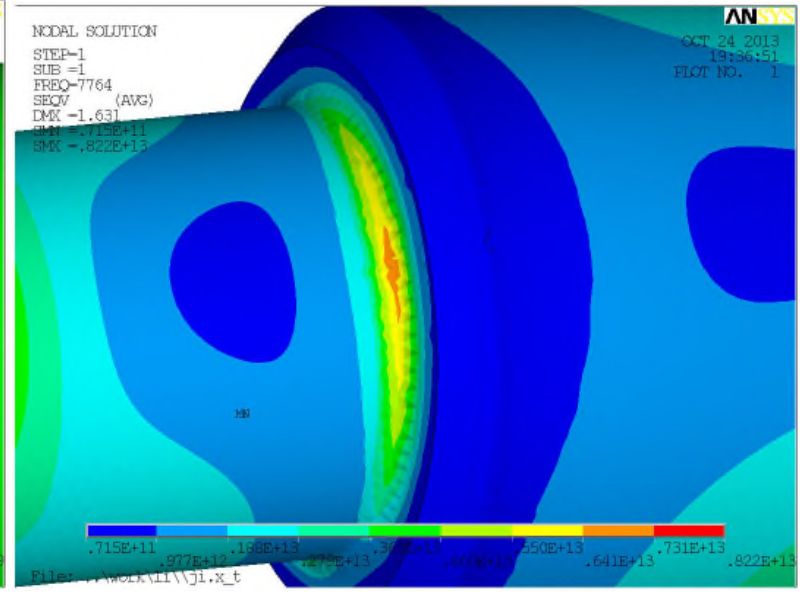

(b) First-order dynamic stress distribution Fig. 1 The simulation of the fan shaft.

The laser shock processing was conducted on the equipment developed by Xi'an Ruida Tian Optoelectronics Technology. The selecting laser energy was $8 \mathrm{~J}$, the spot diameter was $4 \mathrm{~mm}$, the pulse width was $20 \mathrm{~ns}$, and the pulse frequency was $2 \mathrm{~Hz}$. For the high stress concentration of arc center vertical, the researcher shocked vertically, while for the low concentration of arc, small shaft, and transition area, shocked obliquely. The laser beam and shaft form an angle of 45 degree and the light spot bulding was shown in Fig. 2(a). When it impacted obliquely, the projection of spot was elliptical, reducing the power density. Due to the large rounded sectional curvature, absorption protective layer used black plastic and toughness tape. The clamp used 6 degrees of freedom, robot, motion accuracy $\leq 0.2 \mathrm{~mm}$, the maximum angular velocity $<110 \%$, dynamic load was $165 \mathrm{Kg}$. The clamp was able to meet the requirement of laser shock peening testment. The testment of fan shaft laser shock peening was shown in Fig. 2(b).
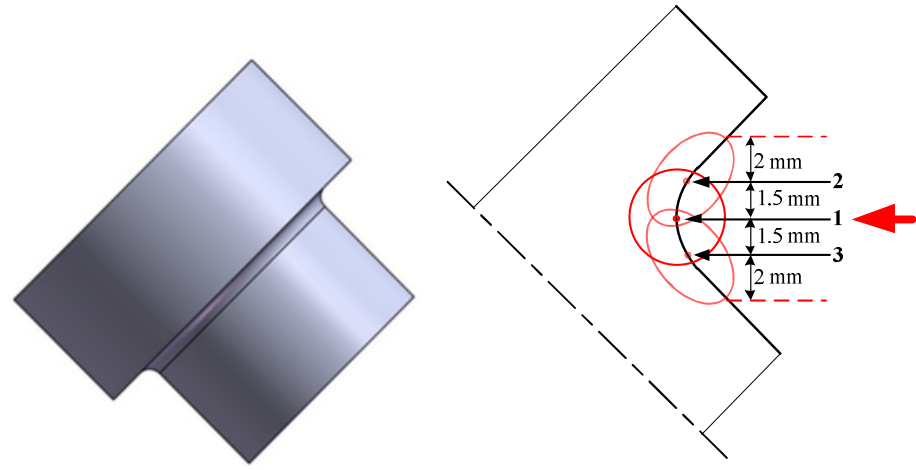

(a) The laser direction and schematic diagram of laser spot overlap

Fig. 2 The schematic diagram of laser shock processing.

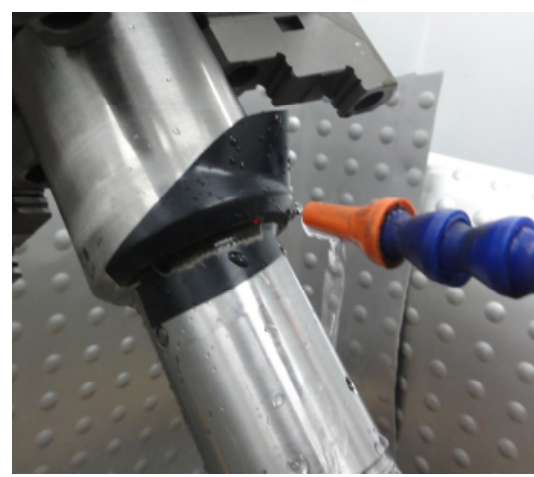

(b) The oblique laser shock peening 


\section{The Experimental Results and Analysis}

The Residual Stress. The stress of the shaft parts can be divided into radial stress, tangential stress, axial stress. The simulation and experimental results of the paper [7] showed that laser shock peening have low affection on axial shaft stress. In the course of shaft parts, the affection of the radial stress was minimal. During the working of the fan shaft, particularly in the starting, stoping, acceleration and deceleration, under the affect of torque, the part was effected by great tangential load and the tangential stress was important for improving the performance of the fan shaft adapter fillet. Therefore, the experiment mainly tested the affection of laser shock peening on tangential stress.

Along the fan shaft fillet, The researcher totally took 7 point and each of the point was $1 \mathrm{~mm}$ from each other. It was shown in Fig. 3. The each point surface residual stress of testment was on Finnish Xstress $3000 \mathrm{XRD}$ and the measurement ethod was testing tilting -fixed $\Psi$ angle. Its tube voltage was $25 \mathrm{v}$, the tube current was $7 \mathrm{Ma}$, Crk $\alpha$ radiation, colltmator diameter was $1 \mathrm{~mm}$, the scanning step angle was $0.1^{\circ}$ the time constant was $0.5 \mathrm{~s}$, the scanning start angle and end angle was $164^{\circ}$ and $145^{\circ}$, the tiliting $\Psi$ angle was $0^{\circ} \sim 45^{\circ}$, the diffraction crystal surface was (211), the stress constan was $\mathrm{Kl}=-318 \mathrm{MPa} /{ }^{\circ}$. The measurement result was shown in Fig. 4.
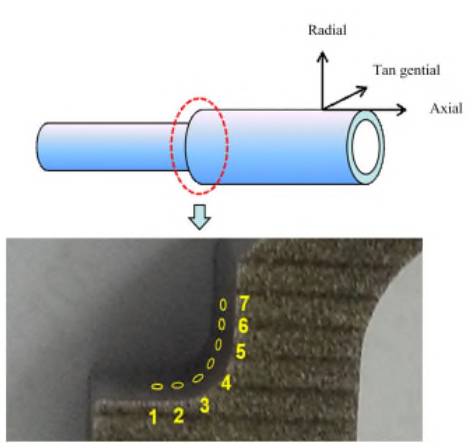

Fig. 3 The residual stress test point.

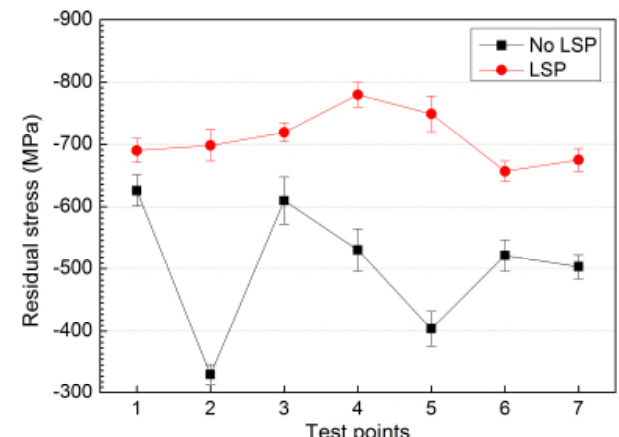

Fig. 4 The stress test with LSP and without LSP.

After laser shock peening, the residual compressive stress at the rounded central region (point 3, 4, 5) improved to $700-800 \mathrm{MPa}$. The stress field near the filet became uniform for $650-700 \mathrm{MPa}$. The LSP improved the inhomogeneity of the original fillet stress distribution and the stress of entire region was high on both sides of low stress characteristic. The residual stress can offset the tensile stress, improving the fatigue resistance [8]. Therefore, the residual stress distribution afer LSP was able to diffuse the stress concentration produced in the fillet region, improving the fatigue strengthe along the weakest fan shaft. A. King er al. tested the TI-6Al-4V alloy grooves for fatigue loading after 1SP. The studies have shown that fatigue loading on the residual stress field have no effect, indicating that the residual stress of fillet-type part had good stability.

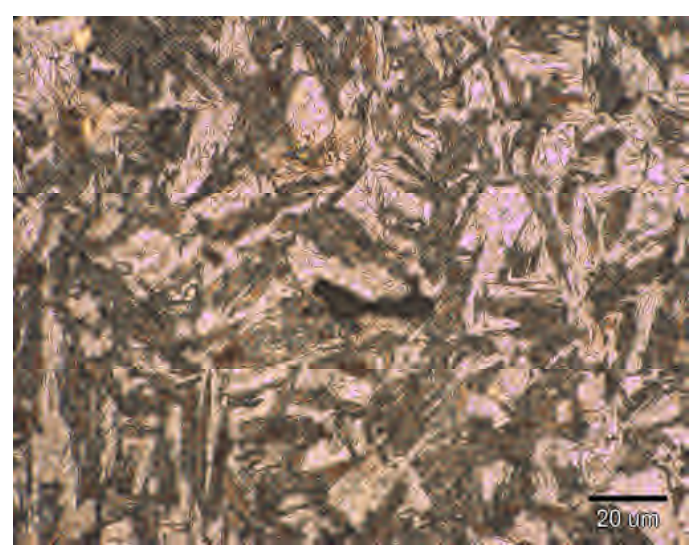

(a) Without LSP treatment

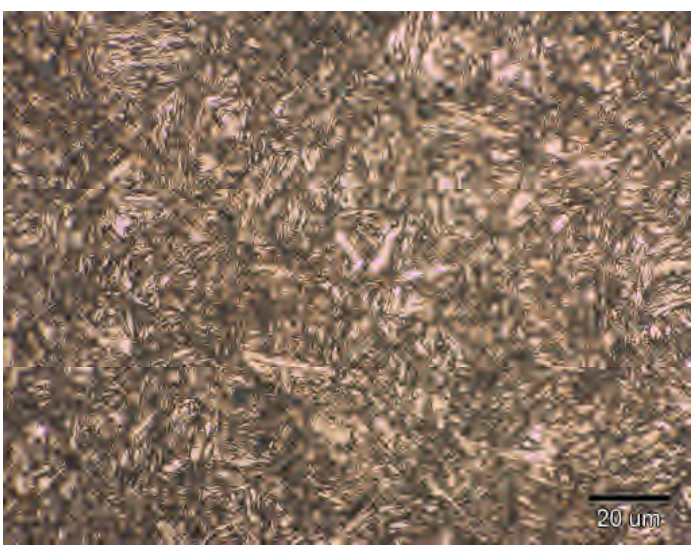

(b) With LSP treatment

Fig. 5 The cross-sectional area of different condition. 
Microstructure. Under the NEOPHPT21 microscope, the researcher observed the metallograph of fan shaft before and after LSP.

The Fig. 5(a), (b) shows comparison of metallograph after LSP. The organization was still martensite but the lamellar became small. The lamellar martensite tissue deoth was about $100 \mathrm{~mm}$. J. $\mathrm{Z}$. Lu et al [9] strengthened the austenitic stainless steel by LSP, refining the surface grain. The reasons were that the material treated by LSP wave produced dislocations and dislocation motion and formed to a new grain boundary. In the martensitic stainless steel, the grain boundary melt during tempering. Therefore, there was not obvious grain structure inside the material. After LSP, the lamellar martensitic microstructure refined and the refinement layer depth exceeded to $100 \mu \mathrm{m}$. The reasons were that the laser shock wave pressures reach to GPA level, transferring energy to the deep inside the material, producing a lot of dislocation motion, accumulating the martensite lamellar tissue, causing martensite division, and finally refining the martensite lamellar tissue. The refinemental martensite microstructure was more uniform and compact, reducing the internal defectsm, decreasing the crack initiation possibility of martensitic stainless steel. As was shown by Fig. 5(b), the $1 \mathrm{Cr} 11 \mathrm{Ni} 2 \mathrm{~W} 2 \mathrm{MoV}$ stainless steel strengthened by LSP, losing the lamellar structure and its depth was $5 \sim 10 \mu \mathrm{m}$.

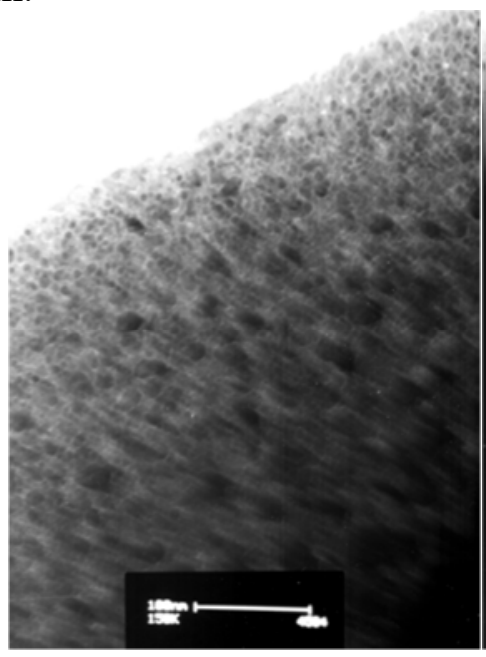

(a) The outmost layer. tissue

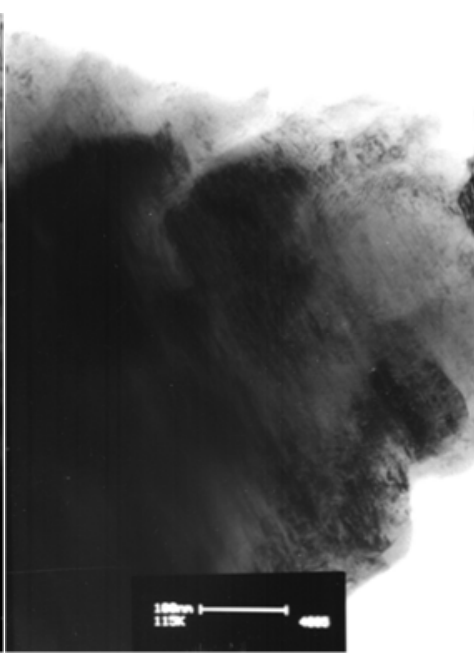

(b) The outmost layer. tissue of $5 \mu \mathrm{m}$ depth

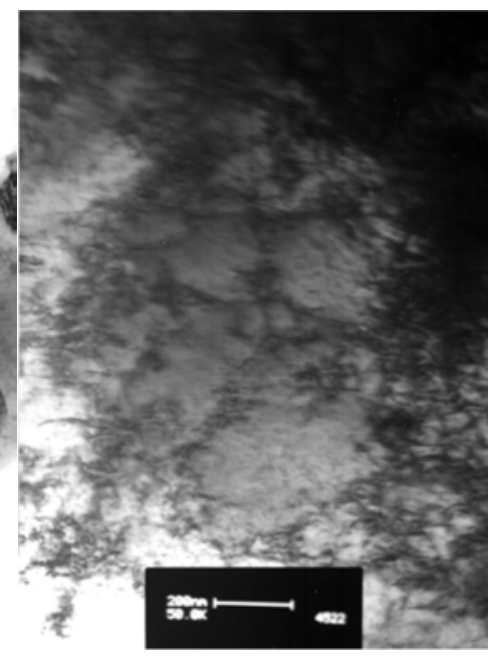

(c) The outmost layer. tissue of $50 \mu \mathrm{m}$ depth
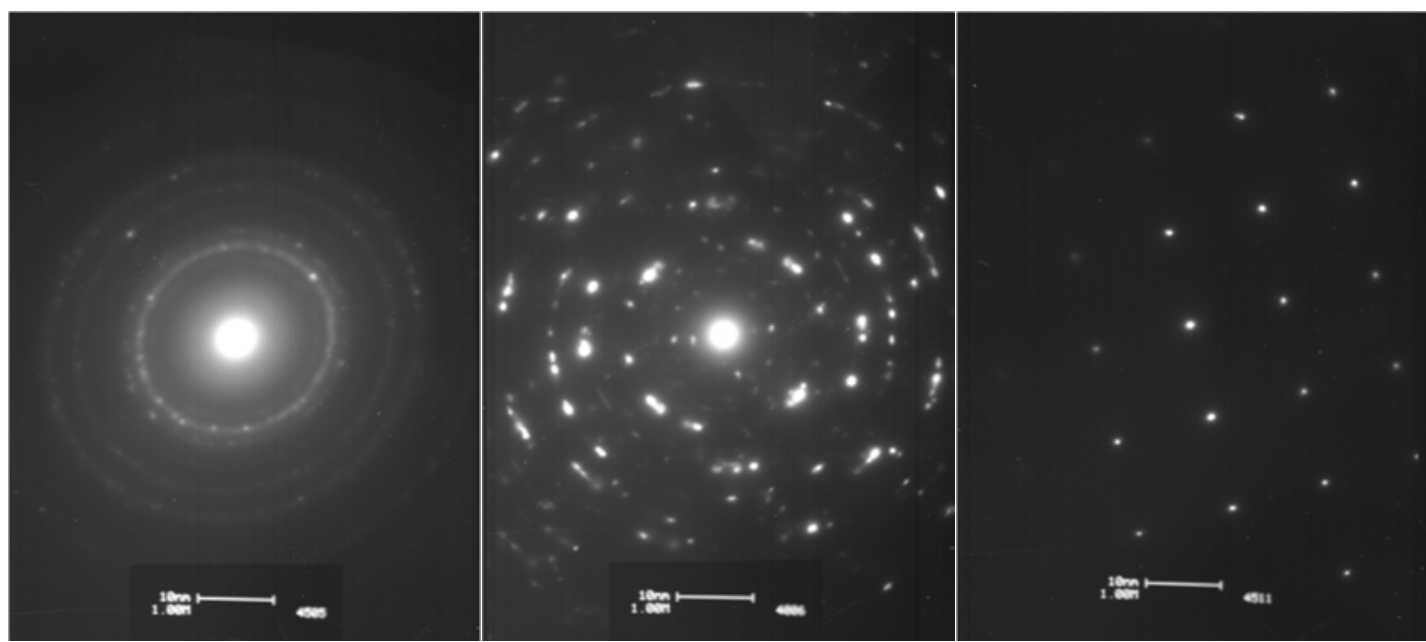

(d) Area A electron diffraction (e) Area B electron diffraction (f) Area C electron diffraction pattern diagram pattern diagram pattern diagram

Fig. 6. The outmost layer tissue with LSP treatment and the electron diffraction pattern diagram

It was shown in Fig. 6(a) and Fig. 6(d), area A electron diffraction pattern by LSP, the outermost layer of $1 \mathrm{Cr} 11 \mathrm{Ni} 2 \mathrm{~W} 2 \mathrm{MoV}$ stainless steel produced nanoscale grains. The size of grain was 5 30nm. It was shown in Fig. 6(e), area B electron diffraction pattern have nanoscale characteristic, indicating 
that there was partly nanoscale grains from the surface of $5 \mu \mathrm{m}$. But it started to transit from nanoscale grains to coarse grains. Fig. 6(c), showed that this position was already normal stainless steel organization, but the TEM images showed that there was a lot of dislocation substructure in the deep layer and the dislocation tangled to form dislocation cellular trend.

The Rotary Bending Fatigue Test and Fracture Analysis. The fan shaft was high speed rotary shaft and the material rotary bending fatigue performance directly reflected the improvement of the fan shaft on mechanical properties. The rotary bending fatigue test achieved the repetitive bending stress effect by rotating the sample. In this case, the bending force was constantly fixed. According "Q/6S 977-2004" standard, the bar sample was made of smooth standard sample and its size was shown in Fig. 7. The rotary fatigue assessment site of the sample processed by LSP and processed the fillet site with obliquely laser shock peening.

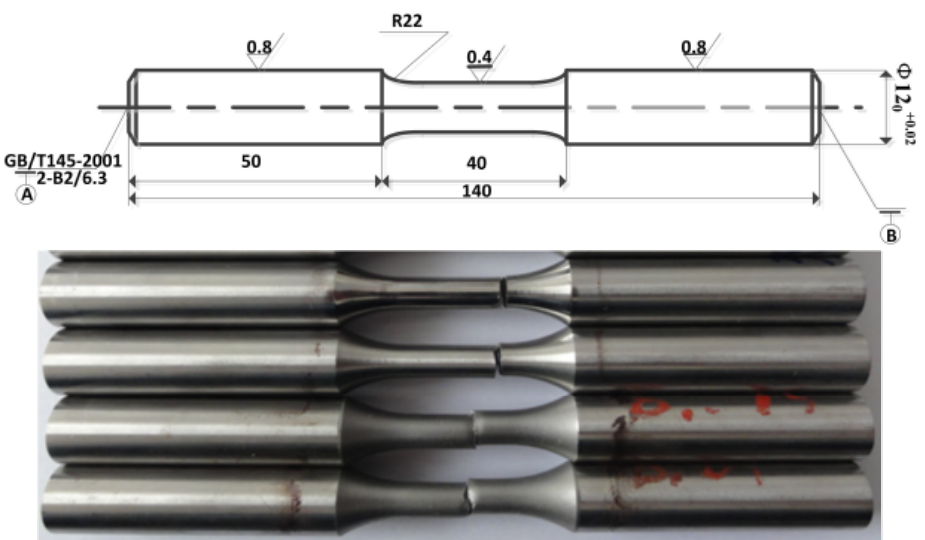

Fig. 7 The rotary bending sample size and the facture location.

According to "GB/T4337-2008" standard, rotary bending fatigue test was conducted at room temperature and air media environment with rotary bending fatigue tester produced by English Lapeer Company. (Rotary velocity: $3500 \mathrm{n} / \mathrm{min}$, load:700MPa, stress ratio : -1). The result was shown in Table 1.

Table 1 . The rotary bending fatigue experimental results.

\begin{tabular}{|c|c|c|c|}
\hline Test condition & Number & $\begin{array}{c}\text { Fatigue cycles } \\
\text { times/week }\end{array}$ & $\begin{array}{c}\text { Average fatigue cycles } \\
\text { times/week }\end{array}$ \\
\hline \multirow{3}{*}{ Original sample } & 1 & $2.15 \times 10^{5}$ & \multirow{2}{*}{$2.00 \times 10^{5}$} \\
\cline { 2 - 3 } & 2 & $2.12 \times 10^{5}$ & \\
\cline { 2 - 3 } & 3 & $1.73 \times 10^{5}$ & \\
\cline { 2 - 3 } LSP sample & 4 & $4.44 \times 10^{5}$ & \multirow{2}{*}{$5.05 \times 10^{5}$} \\
\cline { 2 - 3 } & 5 & $5.67 \times 10^{5}$ & \\
\cline { 2 - 3 }
\end{tabular}

The average cycles of original state was $2 \times 10^{5}$, the laser shock peening sample was $5.05 \times 10^{5}$, which was 2.5 fold than the original state fatigue. The LSP improved 1.5 fold of the fan shaft rotary bending fatigue.

Using the JSM-7001F thermal field emission scanning electron microscope analysised and scaned the fracture.Before and after LSP, the fatigue crack source and expansion area were shown in Fig. 8, and the extension fatigue striepes was shown in Fig. 9. 


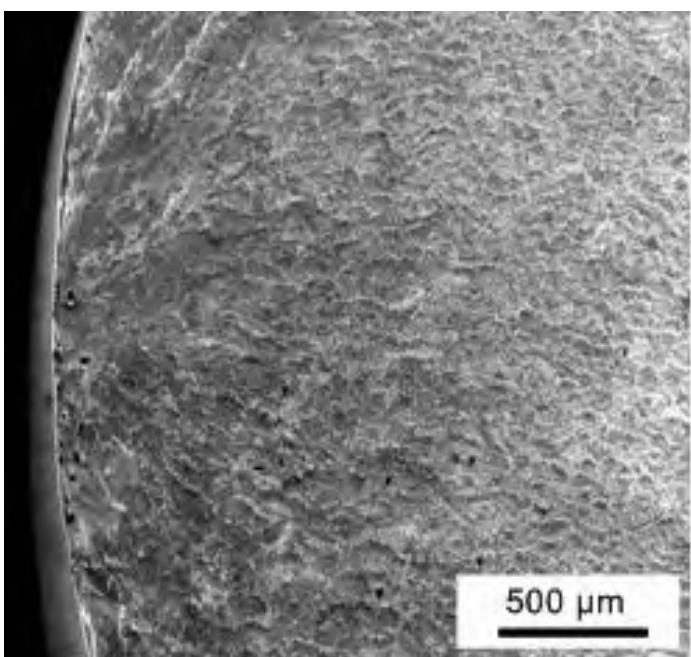

(a) The sample without LSP treatment

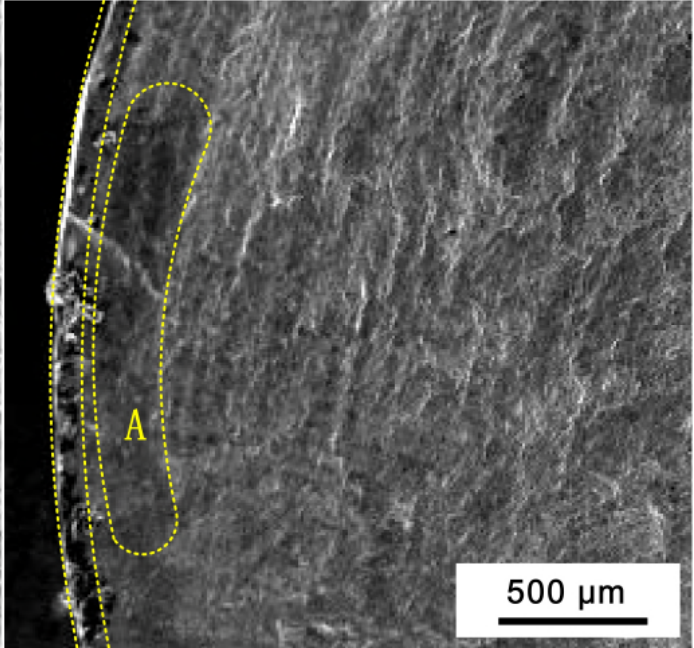

(b) The sample with LSP treatment

Fig. 8 The fracture fatigue crack source area and The expansion area.

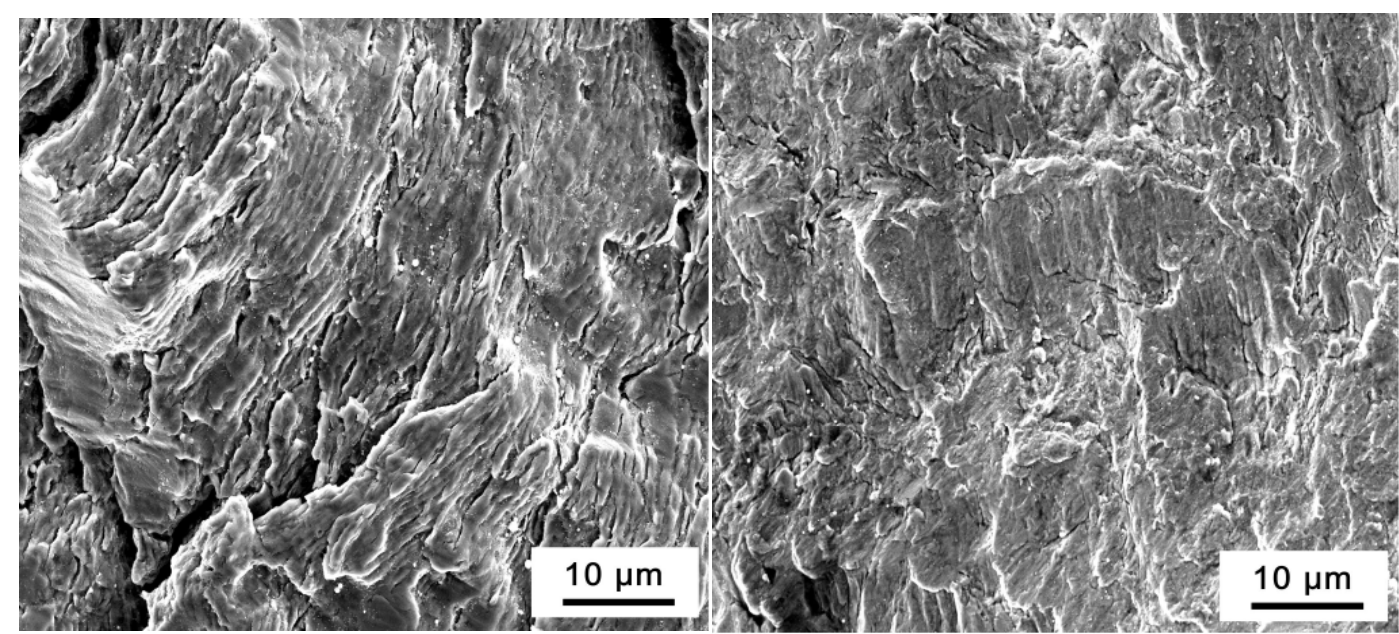

(a) The sample without LSP treatment (b) The sample with LSP treatment Fig. 9 The expansion fatigue crack source area.

Compared by original sample in Fig. 8(a), the LSP sample fatigue source was at subsurface (Fig. $8 \mathrm{~b}$ ). At the beginning of the crack expansion, there was a contrast smooth region (Fig. 8b region A), indicating that the crack expanded slowly. As shown in Fig. 9, LSP sample existed more fatigue stripes in expansion region, and had longer expansion time. It had changed rotary bending fatigue performance in some way.

Comparative analysis by the fracture characteristics showed that the extending life of the LSP sample related with crack initiation and the surface crack expansion. LSP produced a more reasonable distribution of residual stress and surface structure refinement layer, reducing the driving force for crack initiation, slowing the crack growth rate, and improvoing the fatigue life of the fan shaft.

\section{Conclusion}

The research conclusion were as follows:

(1) With oblique laser shocking, the residual stress of the stress concentration region was $700 \sim 800 \mathrm{MPa}$, and the stress field near the transition fillet became uniform for $650 \sim 700 \mathrm{MPa}$, improving the rounded residual stress and the unevn stress of the original fillet, obtaining a better distribution of residual compressive stress, which effectively alleviated the stress concentration. LSP was an effective surface treatment technic for processing the stress concentration region. 
(2) LSP conduced the martensite structure plastic deformation, refining the martensite lamellar tissue with the depth of $100 \mu \mathrm{m}$. With laser shock peening, the surface tissue have lost the lamellar structure reaching nanoscale with width of $5 \sim 30 \mathrm{~nm}$ and depth of $15 \mu \mathrm{m}$.

(3) The rotary bending fatigue life of fan shaft increased by $150 \%$ after by LSP. The fracture analysis indicated that the position of fatigue source after LSP move to the interior material, reducing the crack expansion rate, improving the rotary bending fatigue performance.

\section{References}

[1] Y. H. Li, W. F. He, W. Li, et al. Research on enhancement of aero-engine components fatigue reliability by laser shock processing. The fifth aero-engine reliability academic communication proceedings, 2009, pp. 564-571.

[2] C. H. Yang, P. D. Hodgson, Q. C. Liu, et al. Geometrical effects on residual stresses in 7050-T7451 aluminum alloy rods subject to laser shock peening. J. Mater. Proc. Tech. 201 (2008) 303-309.

[3] A. King, A. Steuwer, C. Woodward, et al. Effects of fatigue and fretting on residual stresses introduced by laser shock peening. Mater. Sci. Eng. A, 435-436 (2006) 12-18.

[4] X. H. Yang, X. D. Tang, M. Q. Xue. The surface strengthening techniques of spheroidal graphite cast iron crankshaft. Mach. Des. Manuf. 1(1) (2011) 151-153.

[5] W. F. He, Y. H. Li, Q. P. Li et al. Experimental Research on laser shock peening of Ni-Based superalloy. Chinese J. Laser. 37(7) (2010) 1898-1902.

[6] Q. P. Li, Y. H. Li, W. F. He, et al. LSP to improve vibration fatigue performance of deflation valve lever. J. Beijing Univ. Aeronaut. Astronaut. 38(1) (2012) 69-74.

[7] R. F. Chen, Y. X. Chen, Y. Q. Hua. Geometrical effects on residual stress in TC4 titanium alloy subject to laser shock processing. J. Jiangsu Univ. (Natural Science Edition), 32(2) (2011) 190-194.

[8] I. F. Pariente, M. Guagliano. About the role of residual stresses and surface work hardening on fatigue $\Delta$ Kth of a nitrided and shot peened low-alloy steel. Surf. Coat. Tech. 202(13) (2008) 3072-3080.

[9] J. Z. Lu, K. Y. Luo, Y. K. Zhang, et al. Grain refinement mechanism of multiple laser shock processing impacts on ANSI 304 stainless steel. Acta Mater. 58 (2010) 5354-5362. 